\title{
Twin-Peaks - What the Knowledge-Based Approach Can Say about the Dynamics of the World Income Distribution
}

\author{
by \\ Andreas Pyka*, Jens J. Krüger^ and Uwe Cantner^ \\ November 1999 \\ INRA-SERD, Université Pierre Mendès France, Grenoble* \\ Department of Economics, University of Augsburg ${ }^{\star}$ \\ pyka@grenoble.inra.fr \\ jens-joerg.krueger@wiso.uni-augsburg.de \\ uwe.cantner@wiso.uni-augsburg.de
}

\begin{abstract}
One of the most recently observed stylised facts in the field of economic growth is the persistent bimodal shape of the world income distribution.. Of course, some theoretical explanations for this new stylised fact already have been provided by neoclassical growth theory within a maximising framework. Although innovation and technology are recognised as being the driving forces behind growth processes, these models maintain the restrictive assumption of a rational acting representative agent. In this paper we draw on a synergetic approach of evolutionary economics. In the model, the countries' productivity development is depicted as a sequence of relative technological levels and the movement from one level to the next higher one is governed by stochastic transition rates. The motivation for these transition rates is based on the knowledge-based approach of evolutionary economics, thereby taking into account depleting technological opportunities, the effects of technological infrastructure and permanent technological obsolescence due to an ubiquitous scientific progress. With this model we are able to show how a persistent bimodal distribution - the twin peaks endogenously emerges via self-organisation. This simulated distribution matches well with the kernel density plot, calculated for GDP per worker data relative to the GDP per worker in the USA over the period 1960-90 for a sample of 104 countries. Both the empirical and theoretical results show an evolution of the density function toward bimodality with a decreasing number of countries with low relative productivity levels and an increasing number of countries with high relative productivity levels, indicating a prevalent catching-up during the period of investigation. However, the separation of both groups of countries is getting more significant over time and therefore further catching-up is expected to become increasingly difficult in the future.
\end{abstract}

Keywords Kernel density - bimodal productivity structure - technological spillovers catching-up - evolutionary process - synergetic approach

JEL O33, C14, N10 


\section{Introduction}

Nicholas Kaldor introduced in 1961 so-called stylised facts into growth theory which represent qualitative characteristics of time series of economic variables, such as per-capita production, capital coefficient, capital intensity, etc. The trend in those data series and the correlation among them are described as a pattern of empirical regularities which should be the main focus of any growth theories and their ability to provide an explanation for these facts is considered as a performance test.

Among Kaldor's list of stylised facts there is one of particular interest for this paper: the growth rate of labour productivity is widely dispersed geographically. Only recently, out of new growth theory another stylised fact has been added which is quite related. Romer (1989) adds that the growth of production cannot be solely explained by an increase in labour and capital input. For both of these stylised facts it is by no means far-fetched to regard technological progress as a main determinant.

Into this discussion only recently a new stylised fact of economic growth has been introduced, the bimodal shape of the distribution of per capita income or the twin-peaked nature of that distribution. This observation suggests that the economies of the world can be divided into two groups: a group with high income - especially the industrialised countries - , and one with low income - among others especially the African countries. These groups are quite sharply separated from each other and catching up of low income per capita countries to the world income frontier is rarely observed and, thus, seems to be a task to be accomplished not easily. Exceptions are well known such as the Japan and the Asian Tigers (see e.g. World Bank (1993), Pack/Page (1994), Nelson/Pack (1999), Krüger/Cantner/Hanusch (2000)). Thus, per capita income or labour productivity is not only dispersed geographically, but this dispersion exhibits a rather stable structure. However, a look at the development of this structure shows that the bimodal shape has appeared only during the past 20 years or so, and is therefore only a recent phenomenon.

A number of studies have been concerned with these sharp and persistent differences in per capita income. It is observed in terms of bi-modal per capita income distributions by Quah (1993a,b; 1996a,b; 1997), Bianchi (1997), Jones (1997), and Paap and van Dijk (1998). It 
shows also up in other work, where in a dynamic context an explanation for internationally different growth rates of countries is searched for such as in as Abramovitz (1986, 1988), Baumol (1986), Fagerberg (1988), and Verspagen (1991, 1992); differences in the respective technological levels seem to be responsible for differences in growth rates and thus for different per capita incomes.

Based on this work, our paper suggests a theoretical explanation for this observation by pointing out the different abilities of various countries in mastering and furthering technological progress. This focus on know-how and technological capabilities as main forces of growth (instead of capital accumulation etc.) is crucial to the knowledge-based approach in innovation theory. Within this theoretical framework we introduce a synergetic model in which countries develop according to their abilities to innovate and their abilities to learn and absorb from others. As these processes are characterised by non-linearities, a bimodal performance structure can be shown to emerge during time. The development and the shape of these structures show a striking similarity to the respective empirical observations.

We proceed as follows: In section 2 we present empirical results on the distribution of per capita income in the world economy, and we briefly discuss attempts to explain these observations. Building on the knowledge-based approach in chapter 3 we develop a selforganising model capable of coping with emerging knowledge and income structures. Chapter 4 concludes the paper.

\section{The Twin Peaks: A New Stylized Fact of Economic Growth}

\subsection{Kernel Density Estimation}

The traditional nonparametric method to visualise a frequency distribution is the histogram. Unfortunately histograms have two main defects as estimators of a density function. First, the shape of a histogram depends on the positions of the bin edges, since data points near the bin edges do not exert any influence on the density estimate in the neighbouring bins. Second, histograms often appear to be quite jagged and therefore make the discrimination between sampling errors and the real structure in the data sample difficult (see Silverman 1986, pp. 7ff.; 
Wand/Jones 1995, pp. 5ff.). Because of these defects of the histogram frequently so-called kernel density estimators are employed in applied statistics and data analysis to smooth the histogram and to eliminate the dependence on the bin edges.

The kernel density estimator ${ }^{1}$ estimates the ordinate of a density function $f(x)$ at a point $\mathrm{x}$ by a weighted average of all $\mathrm{n}$ data points $x_{i}(i=1, \ldots, n)$ of a particular sample, where the weights decrease with an increasing distance of the data points from $x$, that is

$$
\hat{f}(x)=\frac{1}{n h} \sum_{i=1}^{n} K\left[\frac{x-x_{i}}{h}\right] .
$$

The kernel function $K(u)$ is thereby in general assumed to satisfy all properties of a symmetric probability density function $\left(K(u) \geq 0 \forall u, \int K(u) \mathrm{d} u=1, \int u K(u) \mathrm{d} u=0,0<\int u^{2} K(u) \mathrm{d} u<\infty\right)$. In addition to these, all continuity and differentiability properties of the kernel function carry over to the estimated density function. In this work we have chosen the Epanechnikov kernel

$$
K(u)= \begin{cases}0.75 \cdot\left(1-u^{2}\right) & \text { for }|u|<1 \\ 0 & \text { otherwise }\end{cases}
$$

as an optimal kernel in an asymptotic mean integrated squared error sense out of the multitude of possible kernel functions listed for example in Scott (1992, p. 140).

The resulting kernel density estimate is in general hardly affected by the selection of a particular kernel function. In contrast to that, the - likewise to be determined - bandwidth parameter $h$ exerts a great influence on the density estimate. A larger $h$ than appropriate leads to an oversmoothed density with a possible loss of detail contained in the sample data. In face of the likely data errors when using panel data for a broad sample of heterogeneous countries, such an oversmoothing may be less dangerous than drawing far reaching conclusions from spurious details of the density estimate that result only from a too low value for $h$.

Since we only intend to give a qualitative characterisation of the dynamics of the world income

\footnotetext{
${ }^{1}$ There is a growing number of monographs on this subject. See e.g. Härdle (1991), Scott (1992), Silverman (1986), Simonoff (1996) and Wand and Jones (1995).
} 
distribution by the way of an explorative data analysis we do not need the computationally very demanding procedure of cross validation to determine an optimal value of $h$. Instead of that, $h$ is computed here from the following simple rule of thump proposed by Silverman (1986, pp. 47f.)

$h=0.9 \cdot \min \left\{\right.$ standard deviation $\left(x_{i}\right)$, interquartile range $\left.\left(x_{i}\right) / 1.34\right\} \cdot n^{-1 / 5}$

for the Gaussian (standard normal) kernel and adapted to the Epanechnikov kernel through multiplying by the adjustment factor 2.214 (Scott 1992, p. 142). Especially in cases where the data are multimodally distributed this way of bandwidth selection can easily lead to an oversmoothed kernel density estimate, but we argue below that this is not unfavourable to the aims of our study. The whole procedure of kernel density estimation is purely nonparametric in that no assumptions about the characteristics of the distribution density have to be made a priori. The outcome of such an analysis depends exclusively on the information contained in the data and is therefore perfectly suited to investigate such uncertain issues as the shape of the world income distribution and its evolution over time.

\subsection{Data and Empirical Results}

Subject of the kernel density estimates in this paper are the real GDP per worker data of the Penn World Table 5.6 (variable RGDPW) ${ }^{2}$ for 104 countries over the period from 1960 to 1990. For each year we take the real GDP per worker data for the sample countries and divide them by the real GDP per worker figure of the USA in that year. The USA is in all but four years the country with the highest GDP per worker and in the remaining years the USA is very close to the respective leader. This measure of relative labour productivity can also be interpreted as a measure of the technological gap of a country with respect to the USA considered as the technologically most advanced country.

Figure 1 shows the density estimates for all years from 1960 to 1990 in one graph and figure 2 gives four single density estimates for the years 1960, 1970, 1980 and 1990.

\footnotetext{
${ }^{2}$ See Summers/Heston (1991) for a description of the data set and the methods used to compile it.
} 


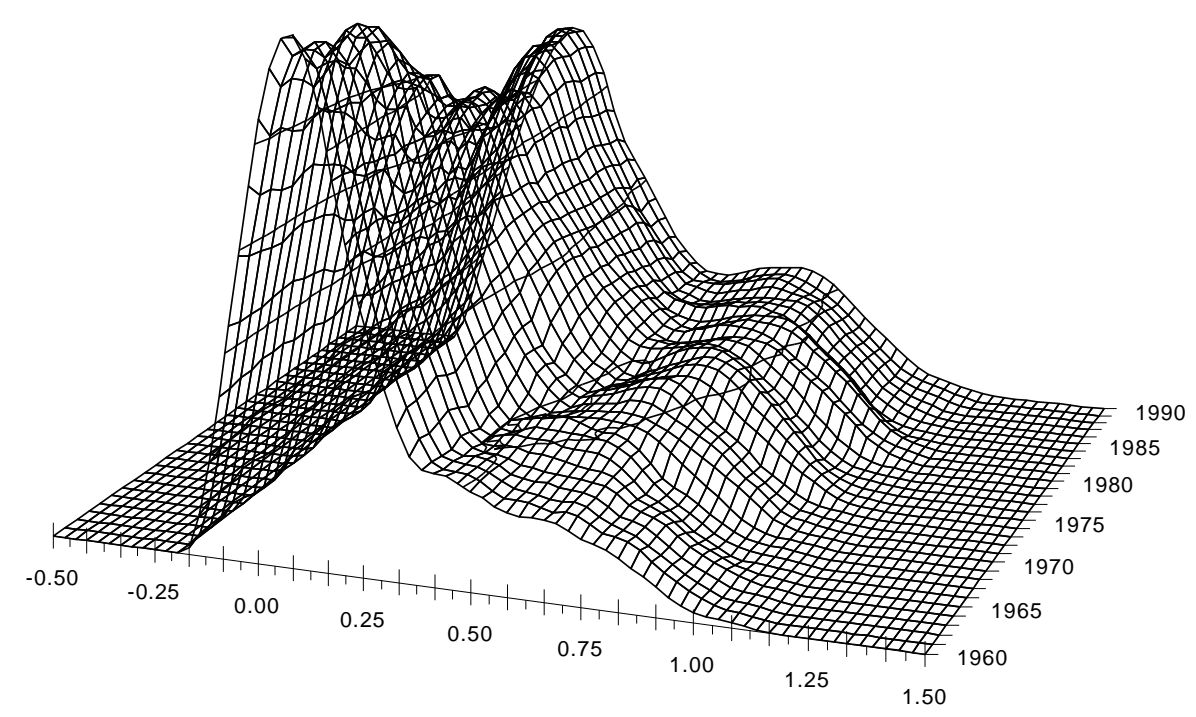

Fig. 1: Estimated productivity distribution $1960-1990$

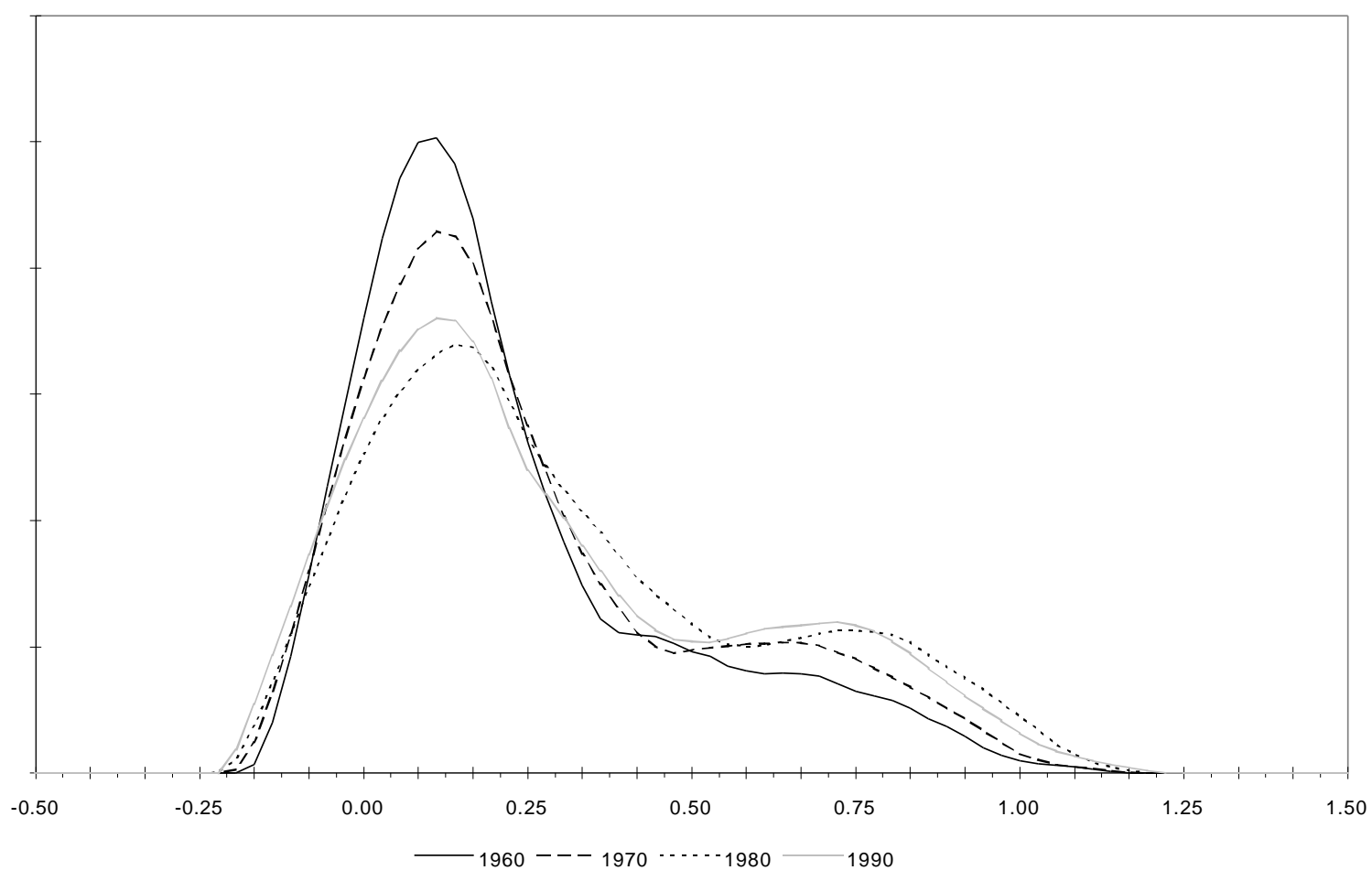

Fig. 2: Income distribution of selected years

From these figures we can obtain various insights into the evolution of the global trends in the distribution of relative real GDP per worker or relative labour productivity during the period of investigation. We are most interested in analysing whether there appears to be a uni- or 
multimodal structure of the distribution of labour productivity and how this structure changes over time. These objectives stand in a close relation to the work of Bianchi (1997), Jones (1997), Paap and van Dijk (1998) and above all to the pioneer in this subject Quah (1993a,b; 1996a,b; 1997). In performing this task the possibility of oversmoothing induced by the bandwidth selection rule is not at all detrimental because it leads to neglecting only weakly appearing modes of the density function and by that in principal discriminates against the result of a multimodal density function. If under these circumstances a bi- or multimodal shaped density function still appears, we can be very sure about its validity.

The figures show in principle an unimodal density function in 1960 with only a weak indication of a second mode. In subsequent years the bimodality of the density function gets more marked and we can observe a large mode in the range of relatively low labour productivity and a second substantially smaller mode in the range of relatively high labour productivity. Over time the position of the first mode shifts somewhat to the right but its shape changes noticeable in that is gets smaller and wider. The second mode also gets wider and shifts to the right by a much larger amount than the first. This change of the shape of the distribution is accompanied by an increasing separation of the two modes. Thus, during the period 1960-90 there have been much more countries able to catch-up to those countries with high labour productivity than the other way around i.e. to fall back. But if the tendency towards a separation of the two modes continues catching up will become increasingly difficult in the future. ${ }^{3}$

The above description of the general tendencies in the evolution of the world income distribution during the whole period of investigation mark some interesting differences between the three decades of our investigation. There has been a substantial reduction of the probability mass under the first mode at low labour productivity in the sixties and seventies, but during the eighties this mode gets larger again. Also the second mode at high labour productivity does no longer shift to the right during the eighties as it has done during the two preceding decades. This again shows that the productivity slowdown after the two oil price shocks is a world wide

\footnotetext{
${ }^{3}$ By its construction the range of the relative labour productivity measure is bounded in the interval $(0, \infty)$ for all years. Despite of that the kernel density estimator calculates positive density values for negative labour productivities. This phenomenon is caused by the so-called boundary bias of kernel density estimation (see Simonoff 1996, pp. 49f.). Silverman (1986, pp. 30f.) has proposed a simple boundary reflection procedure to correct for this bias. The results of the application of this procedure are given in the appendix of this paper. The figures 10 and 11 there make clear that this modification changes the shape of the first mode but does neither affect the bimodality of the estimated density function nor any of the conclusion we draw from figures 1 and 2 in the main text.
} 
phenomenon, as has recently been pointed out by Ben-David and Papell (1998) by determining the dates of trend breaks in the time series of real GDP per capita for 74 countries.

There exist now several other studies that give support to this new stylised fact. Quah (1993a,b; 1996a,b; 1997) uses also nonparametric kernel density estimation techniques and Markov chain methods to investigate the dynamic evolution of the world income distribution. He was the first who became interested in the issue of looking at the whole distribution of incomes rather than looking only at first or second moments as is done in the analysis of $\beta$ - and $\sigma$-convergence in the standard approach of convergence analysis (see Sala-i-Martin 1996). It was also Quah (1996a) who coined the term Twin Peaks to characterise the bimodal shape of the world income distribution. ${ }^{4}$ Other researchers who applied kernel density estimation to different definitions of relative income per capita or per worker reached similar conclusions (see Bianchi 1997; Jones 1997). These results are further enforced by Bianchi (1997) who uses bootstrap multimodality tests to sharpen the conclusions from his kernel density estimates. With these he is able to test for the number of modes in the world income distribution and he rejects the null hypothesis of a single mode in favour of bimodality but is not able to reject the null of bimodality. Paap and van Dijk (1998) depart from the so far used nonparametric framework and fit parametric mixture densities to approximate the world income distribution. Their analysis indicates that a mixture of a Weibull and a truncated normal density performs best and the maximum likelihood estimates of the parameters of this density give also support to the finding of an increasingly bimodal world income distribution.

\subsection{Theoretical Explanations}

\section{(i) neo-classical approaches}

From a theoretical point of view nearly all neo-classical growth models are in principal able to explain a bimodal world income distribution function. This applies to the Solow (1956) model which only predicts conditional convergence as well as to the endogenous growth models (see Aghion/Howitt (1998) and Barro/Sala-i-Martin (1995) for two recent booklength surveys of this important class of models) and other models allowing for multiple equilibria (e.g. Azariadis/Drazen 1990; Greiner/Semmler 1996). In the model of Greiner and Semmler (1996)

\footnotetext{
${ }^{4} \mathrm{He}$ summarises his findings succinctly by writing that "[...] there is a group of the rich, collecting together; a group of the poor, collecting together; and a middle-income class, vanishing" (Quah 1996a, p. 1048).
} 
the fact that the two modes diverge from each other is also captured by a dependence of the growth rates on different parameter values.

In heart of neoclassical growth models is an infinitely lived representative household which maximises lifetime utility subject to a budget constraint. Capital in endogenous growth theory is broadly defined and encompasses not only physical capital but also human and knowledge capital components. The rate of technological progress in these models is determined through the investment decisions of profit maximising firms. Since most of these models are purely deterministic the firms have access to all information they need to come to an optimal decision.

In most of these models a single country or the interaction between two countries is modelled but none of them makes an explicit statement about the dynamics of the entire distribution of a larger group of countries. In criticising empirical work in relation to these theoretical models Durlauf and Quah (1998, p. 59) state: "'explaining distribution dynamics' needs to go beyond representative-economy analysis". Quah (1997) cites some examples of models that try to model distribution dynamics in various fields of economics and using different methods. Quah (1997) himself contributes a model of endogenous coalition formation among countries involving the accumulation of human capital to perform this task.

\section{(ii) evolutionary approaches}

These neo-classical approaches analyse technological and economic interdependencies in a decision-theoretic context with exogenous given technological opportunities. Moreover, this technological opportunity space is taken as homogeneous, symmetric as well as known to all actors. Consequently, any consideration of problems located in the technological sphere which are due to weak or undeveloped technological capabilities or technological infrastructure as well as to technological bottlenecks in situations of decreasing or even depleted technological opportunities are beyond the analytical scope of such a theory.

With modern or evolutionary innovation theory an alternative to this incentive-based neoclassical theory exists. Here, an explicit knowledge-orientation takes into account the role technological capabilities, competencies and infrastructure play in the creation and depletion of technological opportunities. By drawing on a micro- and meso-perspective meanwhile there exists a considerable theoretical and empirical literature to these questions showing how firms 
behave in a non-optimising and bounded rational way to cope with technological problems and intrinsic uncertainty in innovation processes (see e.g. Freeman (1994) for a survey). Out of this, we draw on three aspects relevant for our purposes of modelling a dispersed productivity development on a macroeconomic level: technological opportunities, technological infrastructure and technological obsolescence.

For the description of technological development one of the cornerstones is the concept of technological opportunities. In modern innovation theory several alternative, largely overlapping concepts are introduced to analyse and describe innovation to occur as a punctuated process (Mokyr (1990)) A technological paradigm (Dosi (1982)), a dominant design (Abernathy/Utterback (1975)) or a technological guidepost (Sahal (1985)) describe the scientific frame, the methods applied and the materials and processes used. In this framework the firms in an economy move along technological paths (so-called technological trajectories or innovation avenues) which represent a certain kind and degree of technological opportunity. However, this opportunity space is not unrestricted but usually gets depleted over time with movement along the trajectory. On higher technological levels most often scientific laws are responsible for boundaries and bottlenecks to occur making further technological improvements increasingly difficult to achieve. In this case, the specific or intensive technological opportunities are exploited, or in Machlup's (1984) words: "The more there has been invented the less there is left to be invented."

However, this does not mean that technological development necessarily comes to a rest with depleted intensive opportunities. Besides scientific progress, the role and consequences of it will be discussed below, new technological potentials, so-called extensive technological opportunities, can come into being by certain technological complementarities of ex-ante seemingly unrelated technologies. Among others (e.g. Mokyr (1990), Kodama (1986)) Rosenberg (1994) puts emphasis on these effects of technological recombination or crossfertilisation: "Often an innovation from outside will not merely reduce the price of the product in the receiving industry, but makes possible wholly new or drastically improved products and processes ... such innovations ... open the door for entirely new economic opportunities and 
become the basis for extensive industrial expansion elsewhere." ${ }^{, 5}$ Or to call in Machlup (1984) again: "The more there is invented, the easier it becomes to invent still more."

Nevertheless, for these effects to be effective an economy has to provide for certain prerequisites, summarised under the heading of technological infrastructure. First of all, in a cumulative technological development the potentials out of technological complementarities cannot be realised without having already reached an advanced technological level. This means, to integrate and exploit external knowledge certain capabilities are required which are discussed in the literature under the notion absorptive capacities (Cohen/Levinthal (1989), Cantner/Pyka (1998a)) or receiver competencies (Eliasson (1990)). On the one hand, these capabilities are a by-product of R\&D on a firm level, on the other hand, an active investment in technological fields not immediately directed on recent technological strands is necessary. In this respect one also has to consider the building up of institutions facilitating technology transfer and the emergence of new start-up high-tech companies in an economy etc. (see Justman/Teubal (1996)). These measures aiming at either a broadening of the technological opportunity space or a widening of technological competencies provide for the technological infrastructure of an economy.

Finally, all economies are confronted with a permanent technological and scientific progress. One the one hand, due to standardisation processes, increasing education levels and other positive externalities the lowest technological levels are continuously lifted up. On the other hand, new insights and breakthroughs in the scientific domain continuously open up new higher technological levels on the upper end of the technological space pushing ahead the technological frontier. Both exogenous influences lead to a permanent technological obsolescence of applied technologies. In other words, in a world characterised by a steady evolutionary development, an innovative standstill is similar to a falling in behind in the course of time. Consequently, economies are under a permanent pressure to innovate.

Taking these three aspects together, the incentive-based approach of neo-classical theory is confronted with a knowledge-based approach of evolutionary economics. With this approach

\footnotetext{
${ }^{5}$ Such effects on technological opportunities are equivalently found by considering advances in sciences. Basic science at universities and other research institutes heavily support technical advance and "... provide the basis for the other important forces, that offset diminishing returns to technological opportunity ..." (Klevorick et al. (1995))
} 
the processes of productivity development are based on the development of know-how, which can be described with the creation and exploitation of technological opportunities as a collective evolutionary process based on adequate technological competencies and infrastructure. On this basis, one may ask whether these concepts can explain the specific pattern of productivity development observed in reality, i.e. whether the twin peaks are a knowledge-driven structure.

\section{Self-emerging Twin Peaks}

We are going now to introduce a self-organisation model, originally developed by Cantner/Pyka (1998b) in an industrial economics context, which attempts to analyse the occurrence of knowledge determined structures as discussed in the preceding chapter. For this purpose first the basic structure of the model is presented, then so-called individual transition rates are introduced responsible for success and failure of the economies in improving their productivity levels. Finally, the results of a numerical simulation are compared with the kernel densities calculated in section 2.2.

\subsection{Basic Structure of the Model}

For our model of productivity development we consider a sample of economies in which firms in different sectors are engaged in $\mathrm{R} \& \mathrm{D}$, thereby pushing forward average productivity levels of economies. At the centre of interest of the model are the self-organising features of technological dynamics; this means that we are abstracting from country specific considerations and strategies with respect to economic growth and choose a so-called population perspective (Saviotti/Metcalfe (1991), which allows to single out pure knowledge effects.

Following the discussion in 2.3 we assume for the productivity development (1) that intensive technological opportunities are offered by a technological paradigm, and that (2) the technological development proceeds cumulatively thereby increasingly exhausting this opportunity space. Furthermore, (3) the technological infrastructure, i.e. absorptive capacities, transfer mechanisms etc. is growing with higher technological levels. 
To describe the productivity levels of the different countries we draw on the following representation of a relative technological scale in fig. 3 .

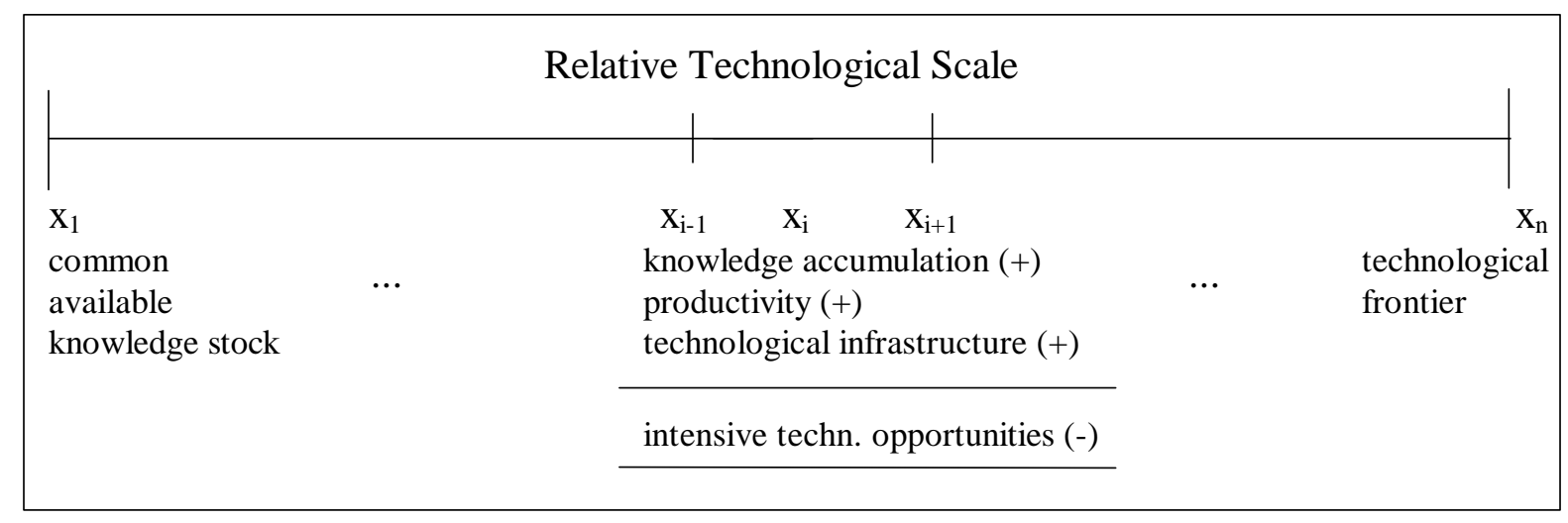

Fig. 3: Relative technological scale

We apply a scale with $n$ different states or technological levels $x_{i}=i / n$ where $i \in\{1, \ldots, n\}$. Each technological state is characterised by the level of accumulated knowledge and a certain degree of technological infrastructure. The assumptions are represented as follows: Productivity levels are cumulatively increasing within this interval. The lowest level $x_{1}$ represents the productivity level going hand in hand with a common available knowledge stock and is considered as a minimum productivity level always achievable. The most sophisticated technological level, the world technological frontier is $x_{n}$ representing the highest productivity level. Technological infrastructure is also assumed to improve along the technological scale, thereby assuming that with higher technological levels also the technological competencies within the economy increase. This means that for realising lower productivity levels drawing on the common available knowledge stock is more or less sufficient, whereas for higher productivity levels specific capabilities become necessary due to a higher degree of complexity of the respective technologies.

In order to investigate long-run productivity developments we interpret the scale as a relative one. Consequently, $x_{n}$ is considered as the best practice productivity level at a certain point in time $t$ and the other states $x_{i}(\mathrm{i} \neq \mathrm{n})$ are to be seen relative to $x_{n}$ (which corresponds to normalising the labour productivity figures of the respective countries by the labour productivity of the USA in each year). Due to scientific progress the technological knowledge of this level will be rated with a lower value in following periods. Equivalently, the common 
available knowledge stock $x_{1}$ is always the lowest productivity level observed. Although in absolute terms the underlying knowledge stock is growing over time, in relative terms it is supposed to stay in a constant distance from $x_{n}$. Again, this matches with the empirical design where not an absolute but a relative measure of labour productivity is considered. Thus the scale can be considered as shifting to the right over time, thereby allowing the investigation of a long time-horizon.

This technological scale allows to model productivity improvements of an economy as movements from state $x_{i}$ to its adjacent neighbour $x_{i+1}$. Taking into account the intrinsic uncertainty of innovation processes, the probability of an economy to move along the relative technological scale is affected by three determinants:

(i) the degree of exploitation of intensive technological opportunities

(ii) the effectiveness of the underlying technological infrastructure and

(iii) technological obsolescence.

These determinants are formalised by means of transition rates. However, before we introduce these main determinants of the model, a few remarks with respect to the synergetic modelling approach applied are necessary.

The introduced relative technological scale can be interpreted as a discrete state-space on which the economies' productivity levels evolve in time. It is analytically tractable with the socalled master-equation approach. This formalism is usually applied to the description of systems composed of many elements whose behaviour cannot be described deterministically. Applying this, the productivity improvement and the respective productivity level achieved by an economy are stochastic. Consequently, the probability to meet a certain productivity level in time $t$ also is a measure for the relative shares of the economies on this productivity level within the whole population. ${ }^{6}$

Which factors affect these shares/probabilities and how do they change? A master equation computes for every single state of the state space the probability to meet this state at a certain point in time $t$. The basic mechanism of this equation is illustrated in fig. 4 .

\footnotetext{
${ }^{6}$ See e.g. Honerkamp (1989).
} 


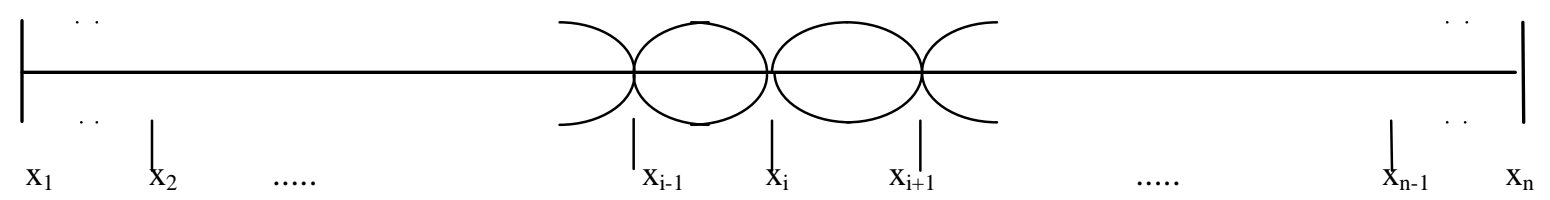

Fig. 4: Basic mechanism of a master-equation

A specific productivity state $x_{i}$ can be left in every infinitesimal small time interval due to two reasons: on the one hand, economies successfully improved their productivity and reach the higher level $x_{i+1}$, on the other hand, technological obsolescence can be responsible for an economy to find itself on a lower productivity level $x_{i-1}$. These movements, indicated by the arrows below the scale, out of the respective state $x_{i}$ decrease its probability. In the same way economies on the lower productivity level $x_{i-1}$ could increase their productivity and find themselves in the state $x_{i}$, or firms on the higher level $x_{i+1}$ fall back on $x_{i}$ because of technological obsolescence. These movements, indicated by the above arrows into state $x_{i}$, increase its probability. In other words, a master equation can be interpreted as a kind of profit and loss account of the probabilities to meet a certain state. The dotted arrows for the respective border states indicate that these states could be either reached or left only from one direction.

\subsection{Transition Rates and Master-Equation}

With the above remarks we are now able to introduce the various factors which influence relative productivity improvement and relative deterioration of productivity levels of an economy. These influences are represented by transition rates between two neighboured states $i$ and $j$.

\section{(i) Exploitation of intensive technological opportunities}

To formalise the effects of a cumulative exploitation of the intensive opportunity space we draw on the technological experience and capabilities going hand in hand with growing productivity levels along the state space. First, with higher productivity levels, economies have a higher chance to accomplish further productivity improvements due to accumulated experiences. However, due to limited intensive technological opportunities, the degree of exhaustion of these opportunities increases with increasing productivity levels, thereby 
decreasing the chance of further success. The interplay of these effects is modelled by applying an exponential formulation and taking into account the cumulative effect. So the probability of productivity improvement at each technological level is given by the following function:

$$
\mathrm{p}_{\mathrm{i}+1 \leftarrow \mathrm{i}}=\alpha \cdot x_{i} \cdot \mathrm{e}^{-\mathrm{d} \cdot \mathrm{x}_{\mathrm{i}}} ; \alpha, \mathrm{d}>0
$$

which describes the probability $p$ of improving from technological level $x_{i}$ to the adjacent level $x_{i+1}(i+1 \leftarrow i)$ by exploiting the intensive opportunity space. This function is illustrated in fig. 5 .

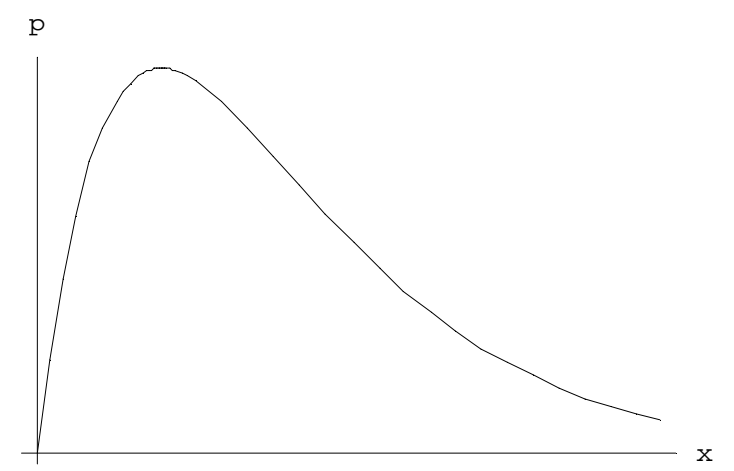

Fig. 5: Exploitation of intensive opportunities

Supposing this distribution, we see that because of accumulated technological competencies at higher productivity levels, the probability for further productivity improvement also increases at the beginning. At a certain level, the impact of a decreased intensive opportunity space begins to dominate with the consequence of decreasing probabilities for further productivity improvements when already higher productivity levels where reached. The size of this effect is determined by the parameter $d$. With higher $d$, the decreasing part of the curve becomes steeper indicating stronger technological boundaries and bottlenecks. $\alpha$ is a weighting parameter.

\section{(ii) Technological infrastructure}

Economies build up technological infrastructure with improving their productivity levels. On the one hand, firms accumulate absorptive capacities ('learning-by-innovating') like other knowledge during the course of time ('learning-by-doing', 'learning-by-using'), on the other hand, institutions of technology transfer are installed, aiming to facilitate the immediate integration and use of new external knowledge (technological spillovers). The probability of 
productivity improvements $r_{i+1 \leftarrow i}$ with respect to technological infrastructure formally is as follows:

$$
r_{i+1 \leftarrow i}=\gamma \cdot x_{i} /\left(1+e^{b\left(g-x_{i}\right)}\right), \quad \gamma, b, g \geq 0, f \in\{0,1\} .
$$

This sigmoid function is given in fig. 6 .

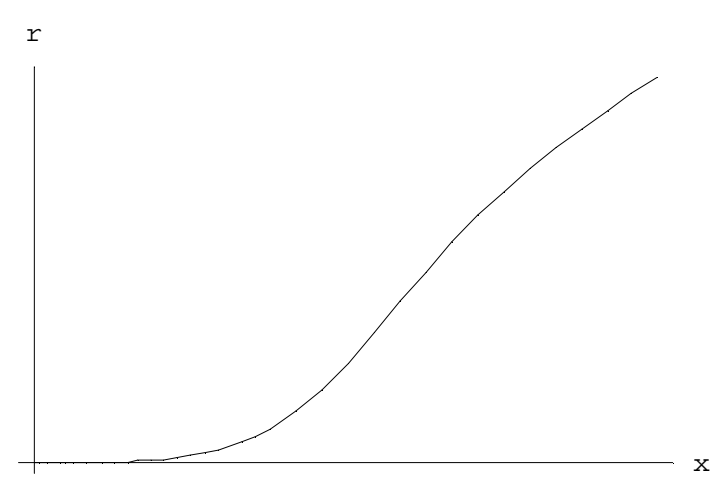

Fig. 6: Technological infrastructure

Parameter $b$ represents the difficulty of building up technological infrastructure. The lower this parameter, the sooner and consequently on lower productivity levels positive effects of drawing on external knowledge thereby realising cross-fertilisation effects i.e. exploring new technological opportunities become possible. With a large $b$ the function becomes rather steep in the middle part and sharply separates productivity levels with a developed technological infrastructure from those without. The parameter $g \in[0,1]$ is a kind of sensitivity parameter which determines the minimum amount of technological competencies for the exploration of extensive opportunities. For relatively small values of $g$ a relative low amount of competencies is necessary to build up technological infrastructure. Parameter $\gamma$ again is a weight.

\section{(iii) Technological obsolescence}

Economies already on high productivity levels face an almost depleted intensive opportunity space. Nevertheless, they potentially can explore extensive opportunities offered by the sciences. Thus, the consequences of a limitation of intensive opportunities are confronted with these new extensive potentials. Besides this, new opportunities provide for the obsolescence of applied technologies. If an economy is not successful, it necessarily will fall behind: in evolution stagnation is equal to come in behindhand. Additionally, this process bears the consequence that ageing technologies become more and more generally available. 
This directly leads to the development of the common available knowledge stock. Because of a generally increasing level of education and certain other externalities (standards etc.), a kind of minimum technological level exists which is a public good and can be used by everybody without additional efforts. On our technological scale this level is represented by the left border $x_{l}$ which continuously moves right because of exogenous scientific progress.

Formally we assume a constant obsolescence $o$ representing these exogenous determinants. Their impact increases on higher technological levels. Because of smaller distances to science higher productivity levels bear a higher technological uncertainty. On our technology-scale the rate of obsolescence $o_{i-1 \leftarrow i}$ is modelled by:

$$
o_{i-1 \leftarrow i}=o \cdot \mathrm{X}_{\mathrm{i}}, \quad 0<o<1 .
$$

Thus, technological obsolescence is represented here as a permanent move to the left of the scale: On the right side higher productivity levels enter the opportunity space of economies, on the left side the common available knowledge stock grows and with it the lowest productivity level $\mathrm{x}_{1}$. This provides for that economies will perform at least this productivity level.

With these above introduced transition rates (1), (2) and (3) we are now able to formulate the master-equation describing the technological dynamics in our model. The transition-rates only depend on the different states $\mathrm{x}_{\mathrm{i}}$ and are time-independent. Therefore, we are dealing with a non-stationary Markov-model which looks as follows: ${ }^{7}$

$$
\begin{aligned}
\frac{d P\left(x_{i} \mid t\right)}{d t}= & p_{i \leftarrow i-1}\left(x_{i-1}\right) P\left(x_{i-1} \mid t\right)-p_{i+1 \leftarrow i}\left(x_{i}\right) P\left(x_{i} \mid t\right) \\
& +r_{i \leftarrow i-1}\left(x_{i-1}\right) P\left(x_{i-1} \mid t\right)-r_{i+1 \leftarrow i}\left(x_{i}\right) P\left(x_{i} \mid t\right) \\
& +o_{i \leftarrow i+1}\left(x_{i+1}\right) P\left(x_{i+1} \mid t\right)-o_{i-1 \leftarrow i}\left(x_{i}\right) P\left(x_{i} \mid t\right)
\end{aligned}
$$

The r.h.s. of equation (4) contains all changes of state $x_{i}$. With positive sign we find the probability increasing, with negative sign the probability decreasing changes. The respective transition rates are multiplied by the probability to meet a specific state $x_{i}$. This is to be interpreted as follows: First, the larger $P\left(x_{i} \mid t\right)$ the higher is the probability of a certain 
transition, i.e. success or failure. Second, with respect to the technological infrastructure effects, the $P\left(x_{i} \mid t\right)$ can also be interpreted as a measure for technological interaction between economies corresponding to international spillovers effects (Coe/Helpman (1995), Coe/Helpman/Hoffmaister (1998)). Here, the specific self-organisational context of the masterequation shows up. The $P\left(x_{i} \mid t\right)$ are to be seen as collective phenomena stating the probability or share of $x_{i}$. This collective magnitude influences the economy-specific transition rates. The reverse influence is given by these transition rates which determine the collective phenomenon.

To close the system, the border equations for state $x_{1}$ and $x_{n}$ have to be formulated separately, because they can be reached from and left in only one direction ('reflecting barriers'). For the lowest productivity level we get:

$$
\frac{d P\left(x_{1} \mid t\right)}{d t}=o_{1 \leftarrow 2}\left(x_{2}\right) P\left(x_{2} \mid t\right)-p_{2 \leftarrow 1}\left(x_{1}\right) P\left(x_{1} \mid t\right)-r_{2 \leftarrow 1}\left(x_{1}\right) P\left(x_{1} \mid t\right) .
$$

With this equation countries on the lowest productivity level are always lifted on the state of common knowledge. The equation for the right border

$$
\frac{d P\left(x_{1} \mid t\right)}{d t}=o_{n-1 \leftarrow n}\left(x_{n}\right) P\left(x_{n} \mid t\right)-p_{n \leftarrow n-1}\left(x_{n-1}\right) P\left(x_{n-1} \mid t\right)-r_{n \leftarrow n-1}\left(x_{n-1}\right) P\left(x_{n-1} \mid t\right) .
$$

reflects the opening up of new opportunities offered by science. With these two equations our model is specified for the numerical simulation.

For the solution of such a system as a first approximation mean-value equations are used in the literature. They have the advantage of being analytically solvable and quite well approximate the solution in the case of uni-modal distributions. But in the case of phase-transitions, meaning that structures bifurcate, the mean-value could describe unlikely solutions. Therefore, we use a numerical simulation analysis to investigate the behaviour of our model.

\subsection{Simulation of the Model}

Before we start with simulation experiments we have to specify the applied parameters and to introduce relative weights for the different determinants of productivity development. The

\footnotetext{
${ }^{7}$ For a detailed formal description of the model see Cantner/Pyka (1998).
} 
probability to reach higher productivity levels of the economies is an aggregate of two different elements. The potentials out of intensive technological opportunities which are given in equation (1) are certainly most important. Because of their outstanding importance these efforts are weighted with $\alpha=0.775$ (around $80 \%$ share in success probability). Decreasing intensive opportunities are reflected by the benching parameter $d=3.5$.

e technological scale.

The impacts of technological infrastructure are the second determinant, given in equation (2). They are most relevant on the second half of the technological scale which is reflected by $g=$ 0.5. Countries have to build up technological infrastructure if they want to realise crossfertilisation effects by exploiting the extensive technological opportunity space. Parameter $b=$ 15 is responsible for a likewise easy accumulation of technological infrastructure and already in the second quarter of the scale allows some positive effects. These effects are weighted with $\gamma$ $=0.225$.

Finally, for the rate of obsolescence (3) we suppose a high impact of the sciences on technological development $(o=0.27)$ with the consequence that on average a new state is potentially reachable on the right side of the technological scale after five periods.

Based on this calibration ${ }^{8}$, equation 7 is the so-called drift-coefficients $\mathrm{K}(\mathrm{x})=\mathrm{p}_{\mathrm{i}+1 \leftarrow \mathrm{i}}\left(\mathrm{x}_{\mathrm{i}}\right)+$ $\mathrm{r}_{\mathrm{i}+1 \leftarrow \mathrm{i}}\left(\mathrm{x}_{\mathrm{i}}\right)-\mathrm{O}_{\mathrm{i}-1 \leftarrow \mathrm{i}}\left(\mathrm{x}_{\mathrm{i}}\right):^{9}$

$$
K\left(x_{i}\right)=x_{i} \cdot\left[\alpha \cdot e^{-d x_{i}}+\gamma \cdot f /\left(1+e^{b\left(g-x_{i}\right)}\right)-o\right] .
$$

For this setting of parameter values we find a drift-coefficient intersecting the $x$-axis three times indicating a multi-modal distribution as solution for our system (fig. 7). Therefore, we have to expect a phase transition of the system. In this case, the mean value equation is not helpful for describing the system, instead a simulation analysis becomes necessary.

\footnotetext{
${ }^{8}$ For a sensitivity analysis of the parameter ranges within which results remain unchanged see Cantner/Pyka (1998b).

${ }^{9}$ See Weidlich, W., Haag, G. (1983), p. 43.
} 


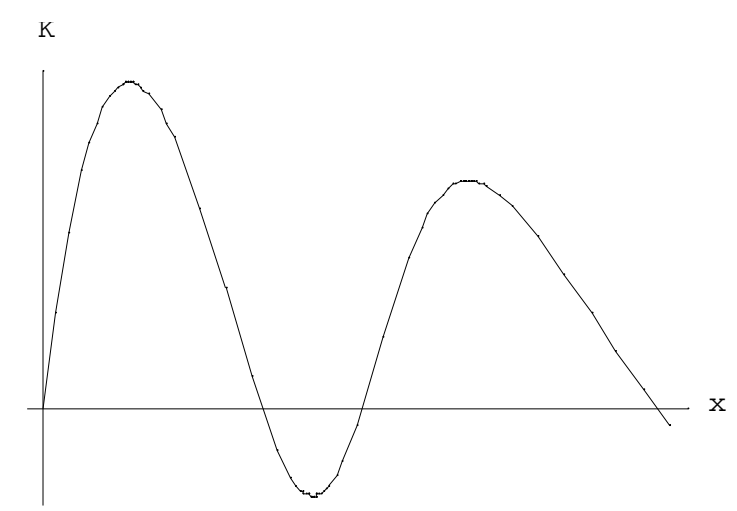

Fig. 7: Drift-coefficients

The simulation of our model is performed for a technological scale with $n=100$ different productivity levels. This choice of $n$ is sufficient to track interesting developmental aspects. All simulation runs are composed of 10,000 iterations. Furthermore, in the simulation all economies start on the lowest productivity level $x_{1}$ (common available knowledge stock) $\left(P\left(x_{1} \mid 0\right)=1\right)$. The distributions of productivity levels over time are shown in fig. 8 .

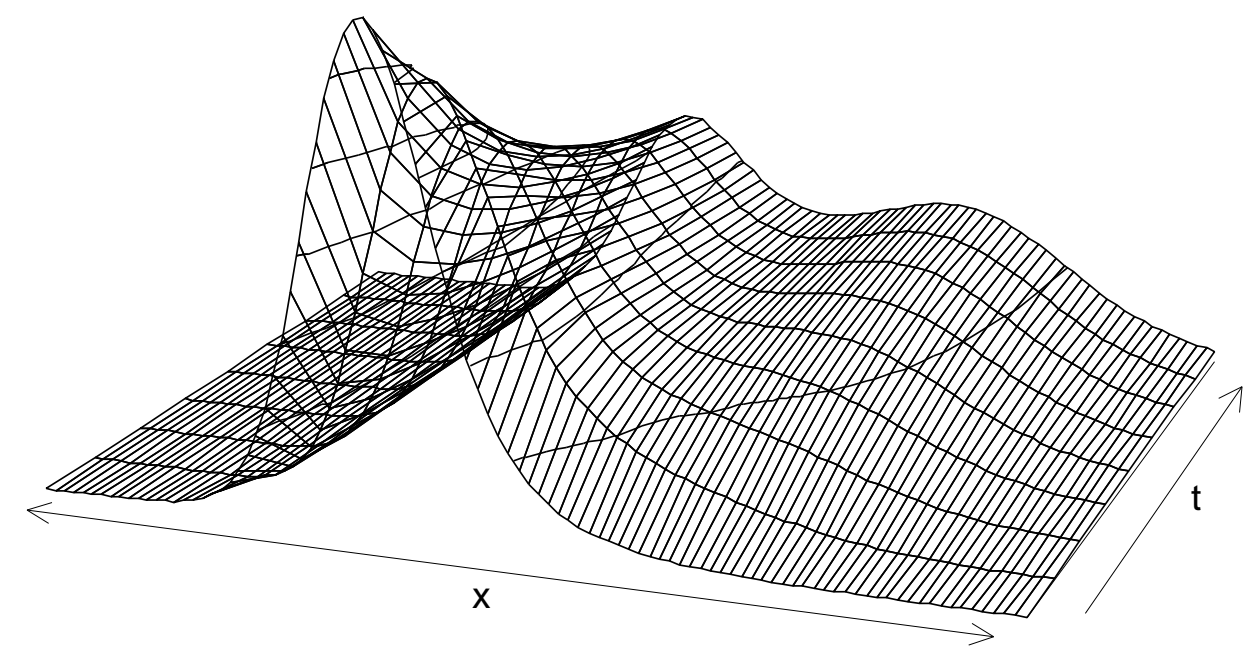

Fig. 8: Simulated productivity distribution over time

All countries start on the technological level $x_{1}$ and therefore no differential technological infrastructures exist. In this phase the intensive opportunity space is not yet exhausted and therefore, fast productivity improvements can be realised in all economies. However, the depletion of intensive technological opportunities soon leads to a slowdown of development 
and first a unimodal structure becomes visible. In the figure we withdraw these early processes, one the one hand for clearness of this graph, on the other hand, to take account of possible distortions due to the chosen starting configuration.

Already at this state of development, some countries have built up considerable technological infrastructure which allows them to draw on extensive opportunities by technological recombination. In this situation, the bulk of lagging countries is confronted with increasingly depleted opportunities; this can already be interpreted as the foundation of the emerging bimodality of the productivity distribution. The impacts of technological infrastructure become even more significant in the course of time leading to the characteristic twin peaked shape. Finally, we find a clear separation of two groups of countries: a likewise larger group staying continuously on smaller productivity levels, and a small group of leading countries, which are successfully maintaining their high productivity levels.

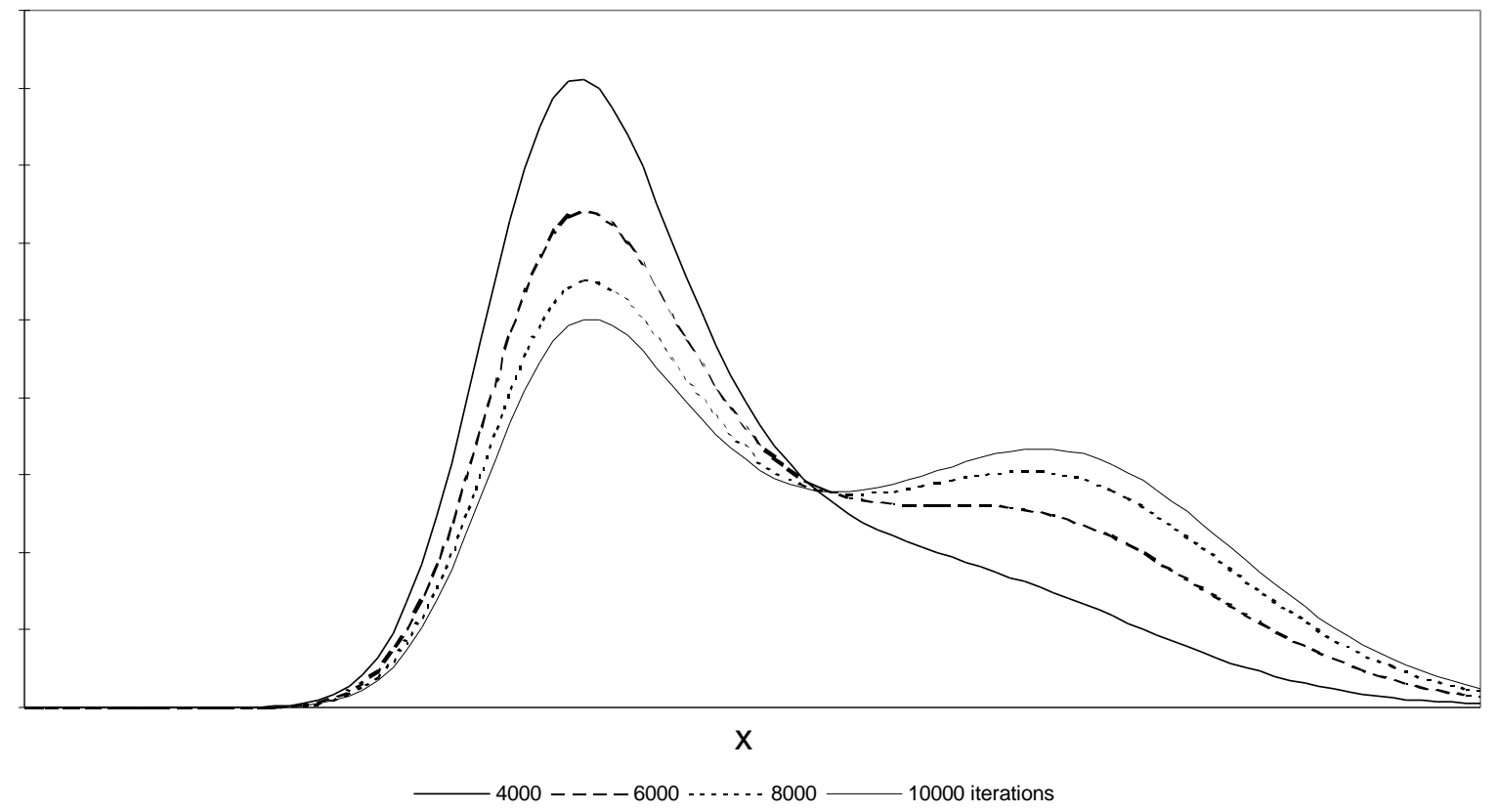

Fig. 9: Productivity distributions for selected iterations (phase portrait)

Fig. 9 shows for selected periods the phase portraits of productivity distribution corresponding to fig. 2 above. By comparing these two figures a striking similarity becomes obvious. Drawing on the knowledge-based approach of evolutionary economics and the theory of selforganisation allows the modelling of the characteristic twin peaks very close to distribution found in reality. 


\section{Conclusions}

This paper deals with the bimodal distribution of per-capita income in the world economy and puts forward an explanation based on the countries' (persistently) different abilities to further and master technological progress. Theoretically, a synergetic model based on the master equation approach has been introduced to show that for certain parameter constellations a bimodal structure of knowledge distribution emerges. The development as well as the shape of this distribution shows a remarkable similarity to the empirically observed one. The latter has been traced for 104 countries for the period between 1960 and 1990 observing drawn from the Summers/Hestons data in the Penn World Table 5.6.

The theoretical approach relies entirely on the accumulation of know-how and the ability to absorb know-how from others. Thus, any kind of capital accumulation or labour force growth is not explicitly taken into account. And therefore the knowledge-based approach is entirely directed to the residual and thus to total factor productivity, although this is not modelled explicitly. Looking at the empirical part of the paper, it is per-capita income and thus labour productivity which is investigated. Quite obviously, there is yet a difference in focus which should deserve some more attention in the future. Moreover, although the similarity of simulation result and empirical observation is striking, in order to test whether the theory holds, requires some more investigation. ${ }^{10}$

Especially the fact of the separation of the two modes needs some more empirical analysis asking for example for the probability of a member in 'club 1' to become a member of 'club 2' in the next period etc. By this, it might be possible to get some empirically determined values for the transition rates applied in the theoretical model. What will happen if those empirical transition rates are included in the simulation? This will be work for the future.

\footnotetext{
${ }^{10}$ It will be very valuable in future work to try to estimate the parameters of the master equation directly by applying the GMM-based method of simulation estimation proposed by Lee and Ingram (1991) (notice that GMM is the abbreviation for the generalized method of moments estimator put forward by Hansen (1982)). Because this method is related to GMM there is no need to specify the complete likelihood function before estimation which would be very difficult in the case of the master equation. Lee and Ingram also give a goodness-of-fit test to judge the overall quality of the estimates.
} 


\section{Appendix}

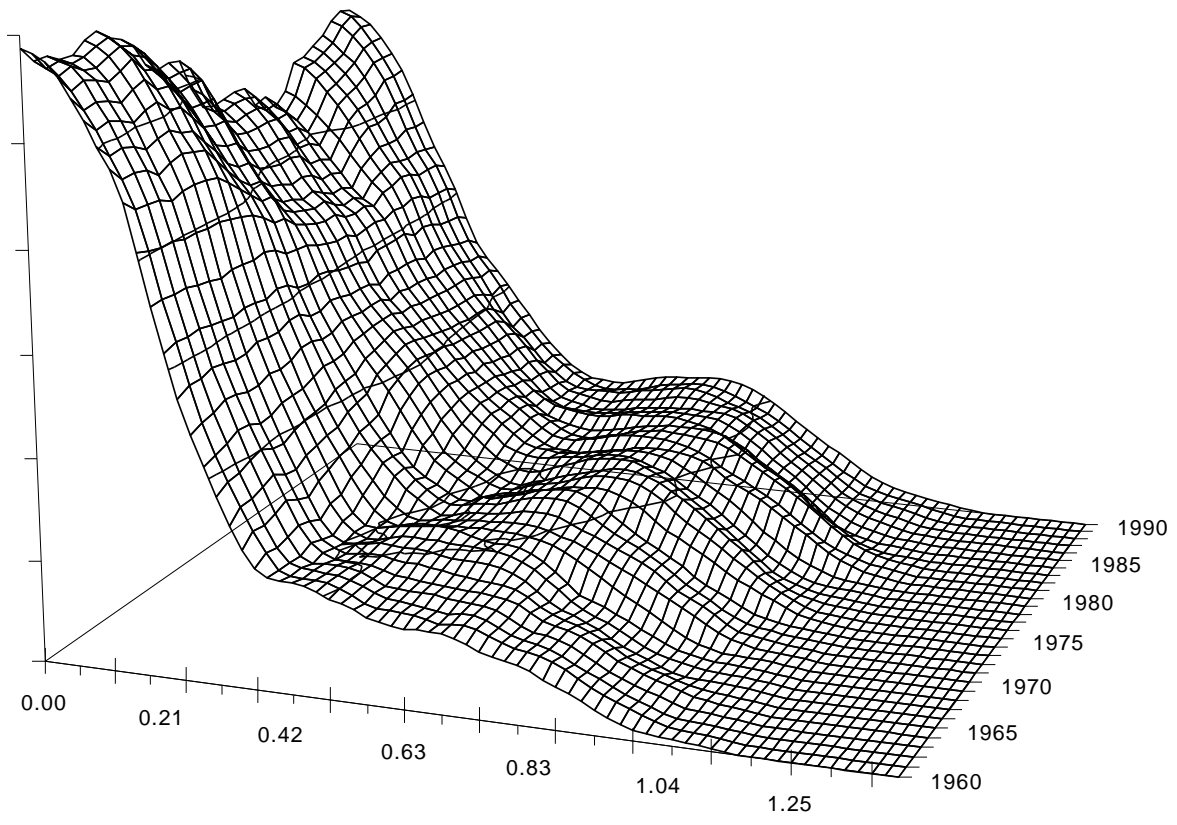

Fig. 10: Estimated productivity distribution 1960 - 1990 with correction for boundary bias

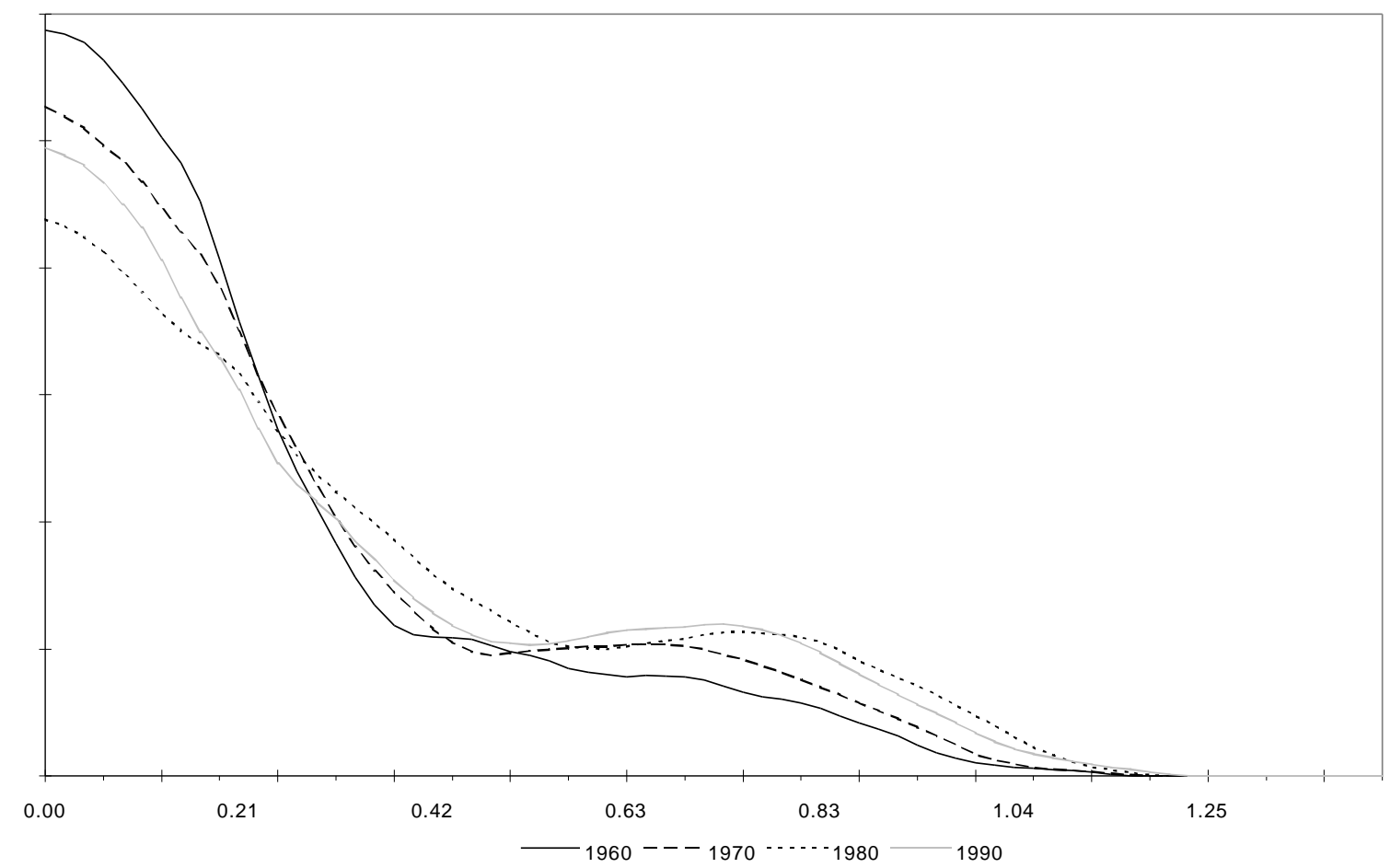

Fig. 11: Income distribution of selected years with correction for boundary bias 


\section{References}

Abernathy, W.J., Utterback, J.M. (1978), Patterns of Industrial Innovation, Technology Review 7, 1978, 41-47.

Abramovitz, M. (1986), Catching Up, Forging Ahead and Falling Behind, Journal of Economic History 46, 1986, 385-406.

Abramovitz, M. (1988), Following and Leading, in H. Hanusch (ed.), Evolutionary Economics - Applications of Schumpeter's ideas, Cambridge, MA: Cambridge University Press, 1988, 323-42.

Aghion, P., Howitt, P. (1998), Endogenous Growth Theory, Cambridge (Mass.): MIT Press, 1998.

Azariadis, C., Drazen, A. (1990), Threshold Externalities in Economic Development, Quarterly Journal of Economics 105, 1990, 501-526.

Barro, R.J., Sala-i-Martin, X. (1995), Economic Growth, New York: McGraw-Hill, 1995.

Baumol W.J. (1986), Productivity Growth, Convergence and Welfare: What Long Run Data Show, American Economic Review 76, 1986, 1072-85.

Ben-David, D., Papell, D.H. (1998), Slowdowns and Meltdowns: Postwar Growth Evidence from 74 Countries, Review of Economics and Statistics 80, 1998, 561-571.

Bianchi, M. (1997), Testing for Convergence: Evidence from Non-Parametric Multimodality Tests, Journal of Applied Econometrics 12, 1997, 393-409.

Cantner, U., Pyka, A. (1998a), Absorbing Technological Spillovers, Simulations in an Evolutionary Framework, Industrial and Corporate Change 7, 1998, 369-97.

Cantner, U., Pyka, A. (1998b), Technological Evolution - An Analysis within the Knowledgebased Approach, Structural Change and Economic Dynamics 9, 1998, 85-108.

Coe, D.T., Helpman, E. (1995), International R\&D Spillovers, European Economic Review, 39, 1995, 859-887.

Coe, D.T., Helpman, E., Hoffmaister, A.W. (1997), North-South R\&D Spillovers, Economic Journal 107, 1997, 134-149.

Cohen, W.M., Levinthal, D. (1989), Innovation and Learning: The Two Faces of R\&D, The Economic Journal 99, 1989, 569-596.

Dosi, G. (1982), Technological Paradigms and Technological Trajectories: A suggested Interpretation of the Determinants and Directions of Technological Change, Research Policy 11, 1982, 147-162.

Durlauf, S.N., Quah, D.T. (1998), The New Empirics of Economic Growth, NBER Working Paper No. 6422, forthcoming in: M. Woodford, J.B. Taylor (ed.), Handbook of Macroeconomics, Amsterdam: Elsevier, 1998.

Eliasson, G. (1990), The Firm as a Competent Team, Journal of Economic Behavior and Organization 19, 1990, 273-298.

Fagerberg, J. (1988), Why Growth Rates Differ?, in: Dosi G., C. Freeman, R. Nelson, G. Silverberg, L. Soete (eds), Technical Change and Economic Theory, London: Pinter, 1988, $432-57$.

Freeman, C. (1994), The Economics of Technical Change, Cambridge Journal of Economics 18, 1994, 463-14.

Greiner, A., Semmler, W. (1996), Multiple Steady States, Indeterminacy, and Cycles in a Basic Model of Endogenous Growth, Journal of Economics 63, 1996, 79-99.

Härdle, W. (1991), Smoothing Techniques: With Implementation in S, New York: Springer, 1991.

Hansen, L.P. (1982), Large Sample Properties of Generalized Method of Moments Estimators, Econometrica 50, 1982, 1029-1054. 
Honerkamp, J. (1989), Stochastische Dynamische Systeme - Konzepte, numerische Methoden, Datenanalysen, Weinheim: VCH Verlagsgesellschaft, 1989.

Jones, C.I. (1997), On the Evolution of the World Income Distribution, Journal of Economic Perspectives 11, 1997, 19-36.

Justman, M., Teubal, M. (1996), Technological Infrastructure Policy (TIP): Creating Capabilities and Building Markets, in: Teubal, M. et al. (eds.), Technological Infrastructure Policy, Dordrecht: Kluwer Academic Publishers, 1996.

Kaldor, N. (1961), Capital Accumulation and Economic Growth, in: F.A. Lutz, D.C. Hague (eds.), The Theory of Capital, London: MacMillan, 1961.

Klevorick, A. et al. (1995), On the Sources and Significance of Interindustry Differences in Technological Opportunities, Research Policy 24, 1995, 185-205.

Kodama, F. (1986), Technology Fusion and the New R\&D, Harvard Business Review, JulyAugust, 1992, 70-78.

Krüger, J.J., Cantner, U., Hanusch, H. (2000), Total Factor Productivity, the East Asian Miracle and the World Production Frontier, Weltwirtschaftliches Archiv, 2000, forthcoming.

Lee, B.-S., Ingram, B.F. (1991), Simulation Estimation of Time-Series Models, Journal of Econometrics 47, 1991, 197-205.

Machlup, F. (1984), The Economics of Information and Human Capital, Princeton University Press, 1984.

Mokyr, J. (1990), The Lever of Riches, New York: Oxford University Press, 1990.

Paap, R., van Dijk, H.K. (1998), Distribution and Mobility of Wealth of Nations, European Economic Review 42, 1998, 1269-1293.

Nelson, R.R., Pack, H. (1999), The Asian Miracle and Modern Growth Theory, Economic Journal 109, 1999, 416-436.

Pack, H., Page, J.M. (1994), Accumulation, Exports, and Growth in the High-Performing Asian Economies, Carnegie-Rochester Conference Series on Public Policy 40, 1994, 199-236.

Quah, D.T. (1993a), Galton's Fallacy and Tests of the Convergence Hypothesis, Scandinavian Journal of Economics 95, 1993, 427-443.

Quah, D.T. (1993b), Empirical Cross-Section Dynamics in Economic Growth, European Economic Review 37, 1993, 426-434.

Quah, D.T. (1996a), Twin Peaks: Growth and Convergence in Models of Distribution Dynamics, Economic Journal 106, 1996, 1045-1055.

Quah, D.T. (1996b), Empirics for Economic Growth and Convergence, European Economic Review 40, 1996, 1353-1375.

Quah, D.T. (1997), Empirics for Growth and Distribution: Stratification, Polarization, and Convergence Clubs, Journal of Economic Growth 2, 1997, 27-59.

Romer, P.M. (1989), Capital Accumulation in the Theory of Long-Run-Growth, in: R.D. Barro (ed.), Modern Business Cycle Theory, Oxford: Basil Blackwell, 1989, 51-127.

Rosenberg, N. (1994), Exploring the Black Box: Technology, Economics and History, Cambridge: Cambridge University Press, 1994.

Sahal, D. (1985), Technological Guideposts and Innovation Avenues, Research Policy 14, 1985, 61-82.

Sala-i-Martin, X. (1996), The Classical Approach to Convergence Analysis, Economic Journal 106, 1996, 1019-1036.

Saviotti, P.P., Metcalfe, J.S. (eds.), Evolutionary Theories of Economic and Technological States, Present Status and Future Prospects, Chur: Harwood Academic Publishers, 1991.

Scott, D.W. (1992), Multivariate Density Estimation: Theory, Practice and Visualization, New York: Wiley, 1992. 
Silverman, B.W. (1986), Density Estimation for Statistics and Data Analysis, London: Chapman\&Hall, 1986.

Simonoff, J.S. (1996), Smoothing Methods in Statistics, New York: Springer, 1996.

Solow, R.M. (1956), A Contribution to the Theory of Economic Growth, Quarterly Journal of Economics 70, 1956, 65-94.

Summers, R., Heston, A. (1991), The Penn World Table (Mark 5): An Expanded Set of International Comparisons 1950-1988, Quarterly Journal of Economics 106, 1991, 327-368.

Verspagen, B. (1991), A New Empirical Approach to Catching Up or Falling Behind. Structural Change and Economic Dynamics 2, 1991, 359-380.

Verspagen, B. (1992), Uneven Growth Between Interdependent Economies - An Evolutionary View on Technology Taps, Trade and Growth, Maastricht: Universitaire Pers Maastricht, 1992.

Wand, M.P., Jones, M.C. (1995), Kernel Smoothing, London: Chapman\&Hall, 1995.

World Bank (1993), The East Asian Miracle: Economic Growth and Public Policy, New York: Oxford University Press, 1993. 